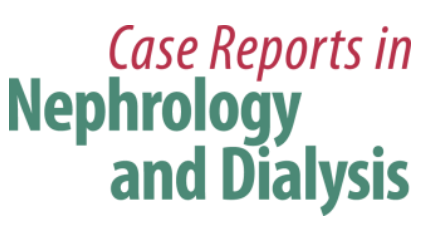

Case Rep Nephrol Dial 2019;9:126-136

DOI: 10.1159/000502682

Published online: September 5, 2019

(C) 2019 The Author(s)

Published by S. Karger AG, Basel

www.karger.com/cnd

This article is licensed under the Creative Commons Attribution-NonCommercial 4.0 International License (CC BY-NC) (http://www.karger.com/Services/OpenAccessLicense). Usage and distribution for commercial purposes requires written permission.

\title{
Donepezil Treatment for Alzheimer's Disease in Chronic Dialysis Patients
}

\author{
Konstantina G. Yiannopoulou ${ }^{a}$ Aikaterini I. Anastasiou $^{b}$ \\ Andreas Kyrozis $^{c}$ Ioannis P. Anastasiou ${ }^{d}$ \\ ${ }^{a}$ Neurologic Department, Henry Dunant Hospital Center, Athens, Greece; \\ bMedical School of Athens, National and Kapodistrian University of Athens, \\ Athens, Greece; 'First Department of Neurology, Medical School, National and \\ Kapodistrian University of Athens, Athens, Greece; dFirst Urology Department, \\ Laiko General Hospital, National and Kapodistrian University of Athens, Athens, \\ Greece
}

\section{Keywords}

Donepezil · Alzheimer's disease · Dialysis · Chronic renal failure

\begin{abstract}
Donepezil is one of the cholinesterase inhibitors that are indicated for the treatment of mild to moderate Alzheimer's disease (AD). Pharmacokinetic analysis has shown that donepezil is primarily eliminated by renal excretion rather than biliary excretion in humans. Therefore, patients with impaired renal function are at high risk of toxicity caused by accumulation of this drug. It is also well known that dialysis patients have very often cholinergic disorders. On the other hand, with the increasing number of long-term chronic dialysis patients, the prevalence of cognitive disorders is increasing in elderly dialysis patients. Because of the above-mentioned special risks of these patients, acetylcholinesterase inhibitors, such as donepezil, are avoided to be prescribed for them. We studied 5 cases of chronic hemodialysis outpatients ( 3 men [70, 72, and 86 years old] and 2 women [65 and 71 years old]) who were diagnosed as having moderate AD. We administered donepezil at $2.5 \mathrm{mg} /$ day orally to the patients. After 1 month's treatment, their behavioral symptoms were improved, without them having any adverse events. We enhanced the dose to $5 \mathrm{mg} /$ day without the patients experiencing any episodes of drug toxicity. After 3 months of treatment with the higher dose, their cognitive and executive functions were slightly improved and their behavioral disorders were remarkably milder, with-
\end{abstract}




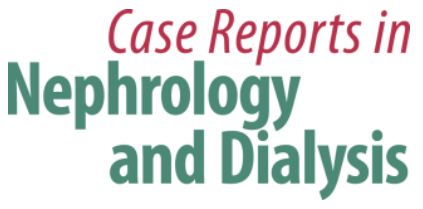

Case Rep Nephrol Dial 2019;9:126-136

DOI: $10.1159 / 000502682$

(c) 2019 The Author(s). Published by S. Karger AG, Basel www.karger.com/cnd

Yiannopoulou et al.: Donepezil for Alzheimer's Disease in Dialysis Patients

out them experiencing any episodes of drug toxicity. The patients' condition remained stable for 6 months after the initial administration of the drug. All of them were followed for the 10 following years, showing a mild cognitive decline per year for the first 5 years and more severe decline for the remaining years of the follow-up. Our cases indicate that donepezil treatment under prudent use may be well tolerated and have a beneficial impact on chronic hemodialysis patients with $A D$.

\section{Introduction}

Donepezil hydrochloride is one of the cholinesterase inhibitors that has been approved for the treatment of mild to moderate Alzheimer's disease (AD) [1]. In general, donepezil is well tolerated. The most frequent adverse events are mild, transient gastrointestinal complaints $[1,2]$.

The pharmacokinetic profile of donepezil in healthy volunteers is characterized by slow clearance and a long half-life (approximately $70 \mathrm{~h}$ ). The long plasma half-life provides stable plasma drug concentrations with once-a-day dosage. Donepezil is metabolized in the liver by the P-450 isoenzyme CYP-3A4 and to a lesser extent by 2D6. The drug is primary eliminated by renal excretion ( $80 \%$ of the administered dose - both as intact drug as well as several metabolites, most of which have been identified) rather than biliary excretion (the remaining $20 \%$ ) in humans [3, 4]. Therefore, patients with impaired renal function are at high risk of toxicity caused by accumulation of this drug. It is also well known that dialysis patients suffer very often from cholinergic disorders. On the other hand, with the increasing number of longterm chronic dialysis patients, the prevalence of cognitive disorders is increasing in this population. Mental impairment in them is associated with increased staff time, hospital days, caregivers burden, health care expenses, and negative impact on patients' quality of life. Furthermore, recent studies showed that older patients on hemodialysis are at substantial risk of being diagnosed with $\mathrm{AD}$, and carrying these diagnoses is associated with a twofold higher mortality [5].

Because of the above-mentioned special risks, acetylcholinesterase inhibitors, such as donepezil, are avoided in patients with severe renal failure. To our knowledge there are only two studies that evaluated the pharmacokinetics of donepezil in patients with impaired renal function $[3,6]$. Their findings suggest that the pharmacokinetics of donepezil does not change in patients with moderately to severely impaired renal function. There is also only one case report with successful donepezil treatment in a chronic dialysis patient [7].

We report 5 cases of chronic hemodialysis patients with moderate $\mathrm{AD}$ who were treated with donepezil.

\section{Case Series}

Our case series study aimed to investigate whether there is a safe dose of donepezil to be administered in chronic dialysis patients with AD.

We studied 5 chronic hemodialysis outpatients ( 3 men [70, 72, and 86 years old] and 2 women [65 and 71 years old]) who were diagnosed as having moderate AD (DSM-IV) [8]. The study subjects underwent a baseline clinical, laboratory, and imaging assessment and a neuropsychological evaluation. The neuropsychological evaluation was repeated every month for the first 6 months. Afterwards they were reevaluated every year for 10 years in total. In 


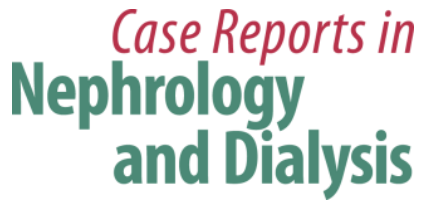

Case Rep Nephrol Dial 2019;9:126-136

DOI: $10.1159 / 000502682$

(c) 2019 The Author(s). Published by S. Karger AG, Basel www.karger.com/cnd

Yiannopoulou et al.: Donepezil for Alzheimer's Disease in Dialysis Patients

the neuropsychological evaluation the Mini-Mental State Examination (MMSE) [9], the Geriatric Depression Scale (GDS) [10], the Neuropsychiatric Inventory (NPI) [11], and the Instrumental Activities of Daily Living (IADL) [12] scale were applied (Fig. 1, 2, 3, 4, 5). All of the applied neuropsychological instruments are validated in Greek patients with AD [9-12]. Taking into consideration that retest effects are apparent in people with dementia despite reduced episodic memory, we used different testing contexts for the monthly administrated MMSE (different words for recalling, objects for naming, and constructional praxis exercises). As a consequence, we did not notice any improvement due to the learning effect of repetition. The only factor that may supported improved results was the lower level of anxiety because of the familiarity of the patients with the whole procedure [13]. Furthermore, Verbal Fluency Tests, Clock Drawing Test, and Trail Making Test Form B were administered every 6 months for the first 5 years and once a year afterwards in order to assess the executive functions in our patients $[14,15]$.

We began donepezil administration with the lower dose of $2.5 \mathrm{mg} /$ day orally and enhanced the dose to $5 \mathrm{mg} /$ day 1 month later. Suwata et al. [7] reported that whenever dialysis was starting $1 \mathrm{~h}$ after the administration of donepezil, an extraordinary elevation appeared in the plasma concentration time curve of donepezil, a fact that was not observed if donepezil was administered at least $5 \mathrm{~h}$ before the dialysis session. Taking into consideration these findings, we followed the same technique keeping, a 5-h interval between donepezil administration and dialysis session.

Unfortunately, in our hospital where the study patients were followed and hemodialyzed, any method of monitoring plasma levels of donepezil or its three metabolites [7] was unavailable. We were reluctant to ask our physically and economically fragile patients for a repetitional measurement in a private laboratory, especially since we noted no clinical sign of elevated levels of the drug, such as bradycardia, diarrhea, or confusion.

After the first month of treatment all patients' behavioral symptoms were diminished while no adverse events were remarked. After 3 months of treatment with the higher dose, their cognitive functions were slightly improved and their behavior was remarkably improved, without them experiencing any episodes of drug toxicity. The patients' initial improvement remained stable for 6 months after the first administration of the drug and almost stable for the first year. All of them were followed for the 10 following years, showing a mild cognitive decline per year for the first 5 years and more severe decline for the remaining years of the follow-up. The same pattern was prominent for their executive functions. Nevertheless, it was remarkable for all the patients that their behavioral symptoms showed some fluctuations over the years, but none of them significantly deteriorated in the behavioral section of the disease for the total treatment period.

All of our patients were of Caucasian origin, of the highest educational level, with mild comorbidities, and with excellent family support.

\section{Case 1}

In a 70-year-old male with a known history of hypertension and on hemodialysis for 3 years prior to neurologic evaluation, a delirium syndrome occurred during his hospitalization for an infection. One month after the resolution of delirium and clinical evidence of infection he was fully evaluated for cognition and behavior. His family stated that his gradual cognitive decline had started 3 years earlier while his behavior had become aggressive 6 months earlier with prominent sleep disturbance, hallucinations during the night, and apathy. He scored 15 in MMSE, 10 in GDS, 42 in NPI, and 3 in IADL. Brain magnetic resonance imaging (MRI) demonstrated notable medial temporal lobe atrophy of grade 2 by the medial temporal 


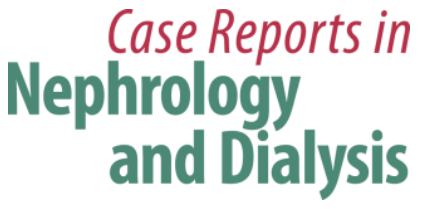

Case Rep Nephrol Dial 2019;9:126-136

DOI: $10.1159 / 000502682$

(c) 2019 The Author(s). Published by S. Karger AG, Basel www.karger.com/cnd

Yiannopoulou et al.: Donepezil for Alzheimer's Disease in Dialysis Patients

lobe atrophy visual rating scale and global cerebral atrophy of grade 2 by the cortical atrophy scale $[16,17]$. A dose of $2.5 \mathrm{mg}$ of donepezil was prescribed and was increased up to $5 \mathrm{mg}$ 1 month later. His cognitive function slightly improved initially and remained plateaued for 5 consecutive years, declining gradually afterwards. His behavior remained disturbed, but with much less aggressiveness and sleep disturbance.

Case 2

A 72-year-old man with a medical history significant for type II diabetes and hypertension and on hemodialysis for 3 years prior to his first neurologic evaluation visited the outpatient memory clinic with complaints of gradual cognitive decline which had started 3 years earlier. He was frustrated by his worsening forgetfulness and his disorientation to time and people. His family also described an obvious depressive symptomatology and an increasing difficulty to maintain hygiene for the previous year. Furthermore, he was often talking to himself or to imaginary others. He scored 14 in MMSE, 11 in GDS, 47 in NPI, and 3 in IADL. He underwent an MRI of the brain which revealed a reduced volume of hippocampi grade 2 on Scheltens et al.'s $[16,17]$ scale and bilateral median and posterior parietal lobe atrophy of the same grade. After confirmation of a diagnosis of AD, he received donepezil $2.5 \mathrm{mg}$ initially and $5 \mathrm{mg}$ 1 month later and citalopram $10 \mathrm{mg}$. His behavior improved rapidly while his cognitive functions followed a more gradual improvement during the first year of follow-up. Afterwards he had a slow deterioration year after year.

\section{Case 3}

A 86-year-old man with a medical history significant for hypertension and on hemodialysis for 2 years prior to his first neurologic evaluation visited the outpatient memory clinic with complaints of sleep disturbance and gradual memory decline which had started 4 years earlier. His family was concerned about his increasing aggressiveness and his depressive mood during the previous 3 months. He scored 18 in MMSE, 14 in GDS, 40 in NPI, and 4 in IADL. Brain MRI demonstrated significant medial temporal lobe atrophy of grade 2, global cerebral atrophy of grade 2, and a reduced volume of hippocampi grade $1[16,17]$. Doses of $2.5 \mathrm{mg}$ of donepezil and $10 \mathrm{mg}$ of citalopram were prescribed and they were increased up to 5 and $10 \mathrm{mg}$ responsively within 1 month. His cognitive function slightly improved initially and remained plateaued for 5 consecutive years, declining gradually afterwards. His behavior remained disturbed but with much less aggressiveness and sleep disorders.

Case 4

A 71-year-old female patient visited the outpatient memory clinic with complaints of gradual cognitive decline which had started 4 years earlier. Her medical history was significant for type II diabetes and hypertension and she had started hemodialysis 3 year earlier. The aggravation in recent memory impairments was more obvious while also apraxia and depression had started 4 months before her visit to our clinic. She mentioned a positive family history of late-onset dementia. She scored 16 in MMSE, 12 in GDS, 23 in NPI, and 7 in IADL. Brain MRI demonstrated significant medial temporal lobe and anterior parietal lobe atrophy of grade 2 and a reduced volume of hippocampi grade $2[16,17]$. ApoE genotyping revealed that she carried one copy of the $\varepsilon 4$ allele [18]. Doses of $2.5 \mathrm{mg}$ of donepezil and $10 \mathrm{mg}$ of citalopram were prescribed and they were increased up to 5 and $20 \mathrm{mg}$ responsively within 1 month. Her cognitive function remained plateaued for 6 consecutive years, declining gradually afterwards. Her depressive symptoms rapidly improved and remained mild. 


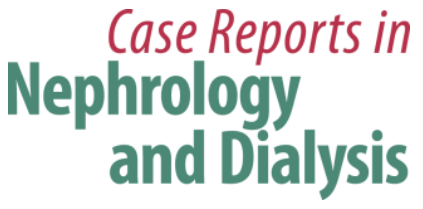

Case Rep Nephrol Dial 2019;9:126-136

DOI: $10.1159 / 000502682$

(c) 2019 The Author(s). Published by S. Karger AG, Basel www.karger.com/cnd

Yiannopoulou et al.: Donepezil for Alzheimer's Disease in Dialysis Patients

Case 5

A 65-year-old female patient was admitted to the nephrology department due to fever and confusion. She had been on hemodialysis for the 2 previous years and she had previously been diagnosed with polyarteritis nodosum. She remained in confusion even after resolution of fever, so a neurologic evaluation was asked for by her nephrologists. The patient was usually lethargic and disoriented to time, space, and persons, with no focal neurologic signs or neck stiffness. Her brain MRI demonstrated significant medial temporal lobe atrophy, global cerebral atrophy, and a reduced volume of hippocampi grade $2[16,17]$. Her family was frustrated by her worsening forgetfulness and depression over the previous 3 years while the patient was avoiding any neurologic evaluation. They also mentioned a strong positive family history of late-onset dementia. A lumbar puncture was performed which revealed normal levels of cells, protein and glucose, but also demonstrated cerebrospinal fluid (CSF) biomarkers indicative of $A D$ : CSF $A \beta_{1-42}$ (marker for $A \beta$ deposition) $427 \mathrm{pg} / \mathrm{mL}$, T-tau (total tau protein) $480 \mathrm{pg} / \mathrm{mL}$, and P-tau 181 (phosphorylated tau at threonine 181) $71 \mathrm{pg} / \mathrm{mL}$ [19]. ApoE genotyping revealed that she carried two copies of the $\varepsilon 4$ allele [18]. Her confusion resolved when she returned home. One month later a neuropsychological evaluation was performed. She scored 16 in MMSE, 15 in GDS, 23 in NPI, and 6 in IADL. Doses of $2.5 \mathrm{mg}$ of donepezil and $10 \mathrm{mg}$ of citalopram were prescribed and were increased up to 5 and $20 \mathrm{mg}$ responsively within 1 month. Her cognitive function significantly improved and remained plateaued for 4 consecutive years, but declined steadily afterwards. Her depressive symptoms slightly improved and remained stable.

\section{Discussion}

Our dialysis patients were diagnosed with moderate AD with an initial MMSE score of 14$18 / 30$. Their cognitive decline started almost simultaneously with their hemodialysis treatment (3-4 years before their first neurologic evaluation) and was accelerated probably because of this stressful event and the concomitant depression due to the sudden lowering of their quality of life. According to recent studies, depression is highly prevalent among hemodialysis patients [20], and additionally it can be prodromal to a component of $\mathrm{AD}$ or a trigger for incipient $\mathrm{AD}[21,22]$. Furthermore, we suppose that depression and accompanying denial of any further medical help was the main reason for the delay of neurologic evaluation in these patients.

Nevertheless, the initial MMSE score was slightly improved (1-3 points for each patient) after 3 months with donepezil $5 \mathrm{mg} /$ day and remained stable for 3 additional months. Their executive functions showed a similar slight improvement, and their behavioral and emotional scores were even more improved. We also remarked that the burden on their family and clinical staff was significantly reduced. They were mildly declined until the 5th year of treatment, when a more rapid cognitive deterioration started to occur. Overall, they remained practically intact in their behavioral status.

It is true that the overall 10-year performance of our dementia patients on dialysis was unexpectedly favorable and beyond our best prognosis. We believe that the highly selective sample of our patients, which was characterized by the presence of many protective factors for survival, was the main reason for the longevity in this group. Reports on survival after a diagnosis of AD vary from 3 to 12 years in general $[23,24]$. Patients with onset of illness before 75 years have a longer life expectancy [24], as do patients who receive donepezil [25], people 


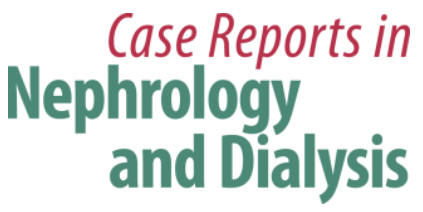

with at least a college degree [26], and those living with family [27]. All of our patients fulfilled the majority of these premises.

It is also interesting and unexpected that all of our patients followed a "slow" progression pattern in their cognitive decline, as indicated by a decrease in the MMSE score of $\leq 1$ point per year [28]. According to Canevelli et al. [28], slow progression of cognitive decline is the most common pattern among $\mathrm{AD}$ patients, with a prevalence of $52 \%$. On the contrary, in a recent study by Stanley et al. [29], the rate of cognitive decline was measured between 1.4 to 2.8 MMSE points per year. We suggest that in our group of patients the high cognitive reserve protected them from an increased rate of cognitive decline [30].

Concerning the issue of survival in our patients as end-stage renal failure patients, we suggest that they followed the global trend of increase in life expectancy that has been observed among patients treated with hemodialysis [31], and also the decline in overall hospitalization rates in these patients [31] and consequently a more stabilized overall outcome. Their special protective factor against mortality in hemodialysis patients is the absence of severe cardiovascular disease in all of them [32].

A $2.5 \mathrm{mg}$ once-daily dose administered $5 \mathrm{~h}$ before dialysis produced no episodes of drug toxicity or adverse events in our patients. We enhanced the dose to $5 \mathrm{mg} /$ day 1 month later and remarked again the same tolerability.

It is known that donepezil is well absorbed, reaching peak plasma concentrations within $4 \mathrm{~h}$ [6]. A 5-h interval following donepezil administration might be beneficial to dialysis patients [7]. The results of $5 \mathrm{mg}$ single-dose trials in patients with impaired renal function compared with patients from a healthy control group indicated no difference in pharmacokinetics of donepezil [32]. Previous findings and our clinical observations suggest that donepezil pharmacokinetics may be unaffected in patients with impaired renal function. On the other hand, we should not forget the primarily renal excretion of the drug and the vulnerability of dialysis patients in cholinergic disorders. Caution in prescribing these drugs in dialysis patients is mandatory.

We recognize that the small number of our patients and the lack of controls are the major limitations of our study. On the other hand, any study not directly relevant to renal function in this particularly vulnerable population of hemodialysis patients is not welcomed by the patients, their relatives, and their nephrologists. We suppose that this is the reason for the nonexistence of any previous studies in this population on donepezil or any other drug for dementia with or without controls, apart from a few case reports. Overall, our cases indicate that donepezil treatment under prudent use may be well tolerated and finally can offer a beneficial impact on chronic hemodialysis patients with AD.

As renal function declines with increasing age and life-sustaining dialysis treatment becomes more often inevitable in the elderly, and as AD primarily affects also them, we believe that the issue deserves further extended studies. Our cases support the possibility of a better quality of life for chronic dialysis patients and their caregivers. Furthermore, recent studies have shown that older patients on hemodialysis are at substantial risk of diagnosis with AD, and carrying these diagnoses is associated with a twofold higher mortality [5]. Consequently, slowing the progression of cognitive decline in these patients might be also life-saving for them. 


\section{Statement of Ethics}

All patients and their caregivers were fully informed about the purpose of the study and provided written informed consent. The study was approved by the Local Ethics and Scientific Committee of the Laiko General Hospital in Athens and was conducted in accordance with the Declaration of Helsinki as revised in 1983.

\section{Disclosure Statement}

All of the authors declare no conflicts of interest.

\section{Author Contributions}

K.G. Yiannopoulou and I.P. Anastasiou conceptualized the study, developed the proposal, coordinated the project, wrote the report, and participated in the overall supervision of the project and revision of the report. A.I. Anastasiou completed the initial data entry and analysis and assisted in the writing and editing of the final report. A. Kyrozis completed the data analysis and depiction and assisted in the writing and editing of the final report and the revision of the report. All authors read and approved the final manuscript.

\section{References}

1 Rogers SL, Friedhoff LT; The Donepezil Study Group. The efficacy and safety of donepezil in patients with Alzheimer's disease: results of a US Multicentre, Randomized, Double-Blind, Placebo-Controlled Trial. Dementia. 1996 Nov-Dec;7(6):293-303.

2 Arai H, Hashimoto N, Sumitomo K, Takase T, Ishii M. Disease state changes and safety of long-term donepezil hydrochloride administration in patients with Alzheimer's disease: Japan-Great Outcome of Long-term trial with Donepezil (J-GOLD). Psychogeriatrics. 2018 Sep;18(5):402-11.

3 Tiseo PJ, Perdomo CA, Friedhoff LT. Metabolism and elimination of 14C-donepezil in healthy volunteers: a single-dose study. Br J Clin Pharmacol. 1998 Nov;46 Suppl 1:19-24.

4 Tiseo PJ, Foley K, Friedhoff LT. An evaluation of the pharmacokinetics of donepezil $\mathrm{HCl}$ in patients with moderately to severely impaired renal function. Br J Clin Pharmacol. 1998 Nov;46 Suppl 1:56-60.

5 McAdams-DeMarco MA, Daubresse M, Bae S, Gross AL, Carlson MC, Segev DL. Dementia, Alzheimer's Disease, and Mortality after Hemodialysis Initiation. Clin J Am Soc Nephrol. 2018 Sep;13(9):1339-47.

6 Nagy CF, Kumar D, Cullen EI, Bolton WK, Marbury TC, Gutierrez MJ, et al. Steady-state pharmacokinetics and safety of donepezil $\mathrm{HCl}$ in subjects with moderately impaired renal function. Br J Clin Pharmacol. 2004 Nov; 58 Suppl 1:18-24.

7 Suwata J, Kamata K, Nishijima T, Yoshikawa T, Sano M. New acetylcholinesterase inhibitor (donepezil) treatment for Alzheimer's disease in a chronic dialysis patient. Nephron. 2002 Jun;91(2):330-2.

8 Dubois B, Feldman HH, Jacova C, Dekosky ST, Barberger-Gateau P, Cummings J, et al. Research criteria for the diagnosis of Alzheimer's disease: revising the NINCDS-ADRDA criteria. Lancet Neurol. 2007 Aug; 6(8):734-46.

9 Mougias AA, Christidi F, Kiosterakis G, Messinis L, Politis A. Dealing with severe dementia in clinical practice: A validity and reliability study of Severe Mini-Mental State Examination in Greek population. Int J Geriatr Psychiatry. 2018 Jun;33(9):1236-42.

10 Fountoulakis KN, Tsolaki M, Iacovides A, Yesavage J, O’Hara R, Kazis A, et al. The validation of the short form of the Geriatric Depression Scale (GDS) in Greece. Aging (Milano). 1999 Dec;11(6):367-72.

11 Politis AM, Mayer LS, Passa M, Maillis A, Lyketsos CG. Validity and reliability of the newly translated Hellenic Neuropsychiatric Inventory (H-NPI) applied to Greek outpatients with Alzheimer's disease: a study of disturbing behaviors among referrals to a memory clinic. Int J Geriatr Psychiatry. 2004 Mar;19(3):203-8.

12 Theotoka I, Kapaki E, Vagenas V, Ilias I, Paraskevas GP, Liappas I. Preliminary report of a validation study of Instrumental Activities of Daily Living in a Greek sample. Percept Mot Skills. 2007 Jun;104(3 Pt 1):958-60. 


\section{Case Reports in Nephrology and Dialysis}

\begin{tabular}{l|l}
\hline DOI: $10.1159 / 000502682$ & (c) 2019 The Author(s). Published by S. Karger AG, Basel
\end{tabular}
www.karger.com/cnd

Yiannopoulou et al: Donepezil for Alzheimer's Disease in Dialysis Patients

13 Gross AL, Chu N, Anderson L, Glymour MM, Jones RN; Coalition Against Major Diseases. Do people with Alzheimer's disease improve with repeated testing? Unpacking the role of content and context in retest effects. Age Ageing. 2018 Nov;47(6):866-71.

14 Faria CA, Alves HV, Charchat-Fichman H. The most frequently used tests for assessing executive functions in aging. Dement Neuropsychol. 2015 Apr-Jun;9(2):149-55.

15 Tsolaki M, Iakovidou V, Papadopoulou E, Aminta M, Nakopoulou E, Pantazi T, et al. Greek validation of the seven-minute screening battery for Alzheimer's disease in the elderly. Am J Alzheimers Dis Other Demen. 2002 May-Jun;17(3):139-48.

16 Scheltens P, Pasquier F, Weerts JG, Barkhof F, Leys D. Qualitative assessment of cerebral atrophy on MRI: inter- and intra-observer reproducibility in dementia and normal aging. Eur Neurol. 1997;37(2):95-9.

17 Scheltens P, Leys D, Barkhof F, Huglo D, Weinstein HC, Vermersch P, et al. Atrophy of medial temporal lobes on MRI in "probable" Alzheimer's disease and normal ageing: diagnostic value and neuropsychological correlates. J Neurol Neurosurg Psychiatry. 1992 Oct;55(10):967-72.

18 Zhao N, Liu CC, Qiao W, Bu G. Apolipoprotein E, receptors, and modulation of Alzheimer's disease. Biol Psychiatry. 2018 Feb;83(4):347-57.

19 Niemantsverdriet E, Valckx S, Bjerke M, Engelborghs S. Alzheimer's disease CSF biomarkers: clinical indications and rational use. Acta Neurol Belg. 2017 Sep;117(3):591-602.

20 El Filali A, Bentata Y, Ada N, Oneib B. Depression and anxiety disorders in chronic hemodialysis patients and their quality of life: A cross-sectional study about 106 cases in the northeast of morocco. Saudi J Kidney Dis Transpl. 2017 Mar-Apr;28(2):341-8.

21 Bica T, Castelló R, Toussaint LL, Montesó-Curto P. Depression as a Risk Factor of Organic Diseases: An International Integrative Review. J Nurs Scholarsh. 2017 Jul;49(4):389-99.

22 Herbert J, Lucassen PJ. Depression as a risk factor for Alzheimer's disease: genes, steroids, cytokines and neurogenesis - what do we need to know? Front Neuroendocrinol. 2016 Apr;41:153-71.

23 Zanetti O, Solerte SB, Cantoni F. Life expectancy in Alzheimer's disease (AD). Arch Gerontol Geriatr. 2009;49 Suppl 1:237-43.

24 Kua EH, Ho E, Tan HH, Tsoi C, Thng C, Mahendran R. The natural history of dementia. Psychogeriatrics. 2014 Sep;14(3):196-201.

25 Meguro K, Kasai M, Akanuma K, Meguro M, Ishii H, Yamaguchi S. Donepezil and life expectancy in Alzheimer's disease: a retrospective analysis in the Tajiri Project. BMC Neurol. 2014 Apr;14(1):83.

26 Tom SE, Hubbard RA, Crane PK, Haneuse SJ, Bowen J, McCormick WC, et al. Characterization of dementia and Alzheimer's disease in an older population: updated incidence and life expectancy with and without dementia. Am J Public Health. 2015 Feb;105(2):408-13.

27 Feng Z, Falkingham J, Liu X, Vlachantoni A. Changes in living arrangements and mortality among older people in China. SSM Popul Health. 2016 Nov;3:9-19.

28 Canevelli M, Kelaiditi E, Del Campo N, Bruno G, Vellas B, Cesari M; ICTUSDSA group. Predicting the Rate of Cognitive Decline in Alzheimer Disease: Data From the ICTUS Study. Alzheimer Dis Assoc Disord. 2016 Jul-Sep;30(3):237-42.

29 Stanley K, Whitfield T, Kuchenbaecker K, Sanders O, Stevens T, Walker Z. Rate of Cognitive Decline in Alzheimer's Disease Stratified by Age. J Alzheimers Dis. 2019;69(4):1153-60.

30 Johansen KL. Life Expectancy Gains for Patients with ESRD. Clin J Am Soc Nephrol. 2018 Jan;13(1):11-2.

31 Neild GH. Life expectancy with chronic kidney disease: an educational review. Pediatr Nephrol. 2017 Feb; 32(2):243-8.

32 Rogers SL, Friedhoff LT. Pharmacokinetic and pharmacodynamic profile of donepezil HCl following single oral doses. Br J Clin Pharmacol. 1998 Nov;46 Suppl 1:1-6. 


\section{Case Reports in Nephrology and Dialysis}

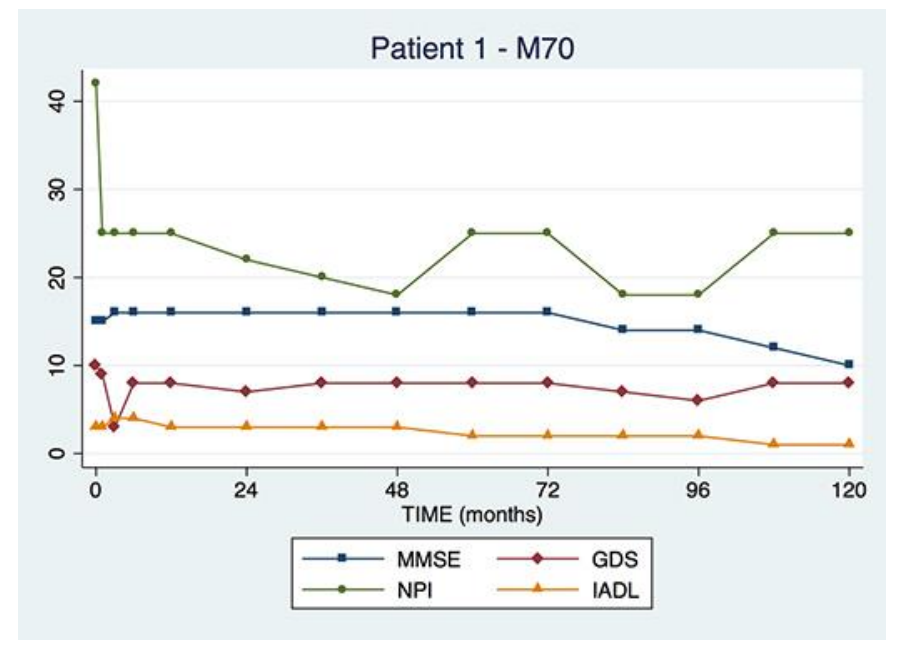

Fig. 1. Score fluctuations for every questionnaire for patient 1 in relationship to time.

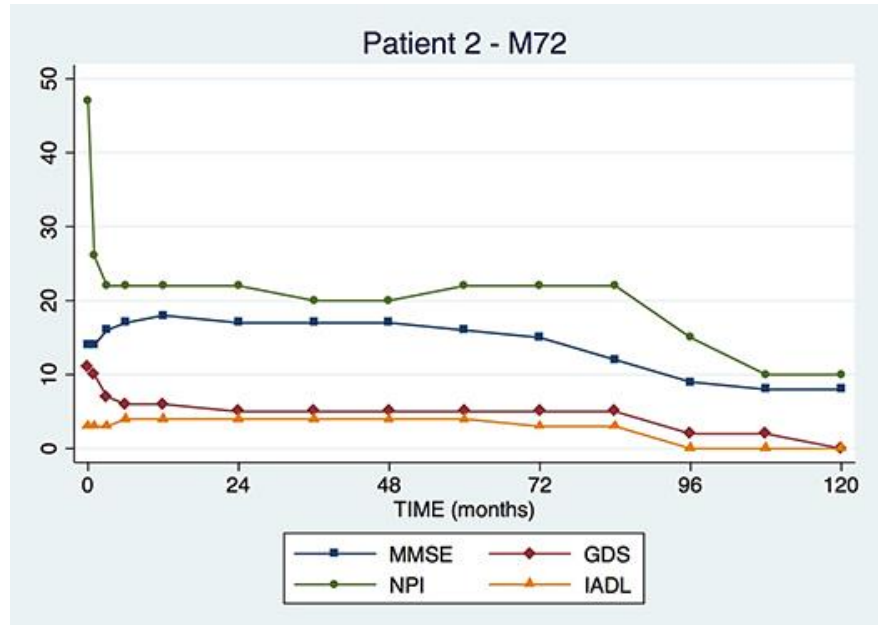

Fig. 2. Score fluctuations for every questionnaire for patient 2 in relationship to time. 


\section{Case Reports in Nephrology and Dialysis} www.karger.com/cnd

Yiannopoulou et al.: Donepezil for Alzheimer's Disease in Dialysis Patients

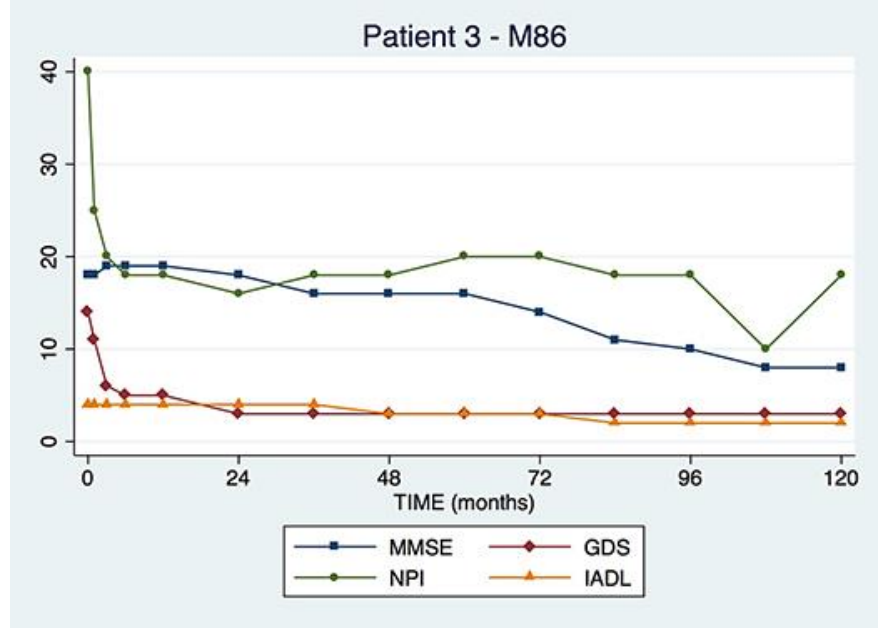

Fig. 3. Score fluctuations for every questionnaire for patient 3 in relationship to time.

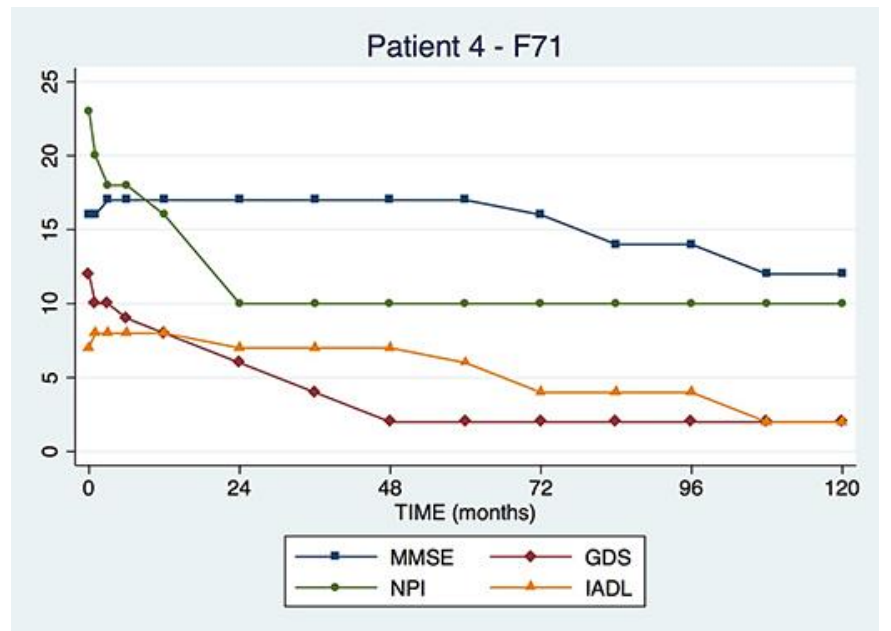

Fig. 4. Score fluctuations for every questionnaire for patient 4 in relationship to time. 


\section{Case Reports in Nephrology and Dialysis}

(c) 2019 The Author(s). Published by S. Karger AG, Basel www.karger.com/cnd

Yiannopoulou et al.: Donepezil for Alzheimer's Disease in Dialysis Patients

Patient 5 - F65

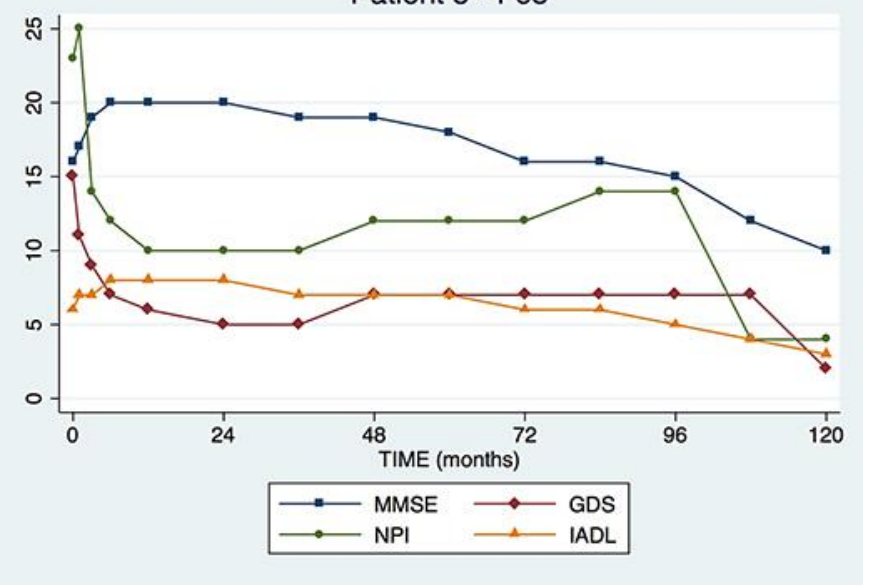

Fig. 5. Score fluctuations for every questionnaire for patient 5 in relationship to time. 